\title{
Orlando'nun Hemşirelikte Etkileşim Modeline Göre Covid-19 Pozitif Lohusanın Hemşirelik Bakımı: Olgu Sunumu
}

\author{
Using The Orlando's Nursing Process To Nursing Care for A Puerperant Woman Diagnosed with Covid 19: \\ Case Report
}

\author{
Nazlı Emel ÖZER YURDAL ${ }^{1}$, Hilmiye AKSU ${ }^{2}$
}

\begin{abstract}
ÖZ
Profesyonel bir meslek olan hemşirelik alanında model kullanımı son dönemlerde giderek artmaktadır. Modeller hemşirelere eğitim, araştırma, uygulama alanlarında rehberlik görevi görürler. Profesyonel olan hemşirelik mesleğini diğer meslek gruplarından ayırarak hastaya sunulan bakımın kalitesini artırır. Kullanılan modellerden birisi de Orlando'nun hemşirelikte etkileşim modelidir. Lohusalık dönemi, anne bebek ve aile üyeleri arasındaki sağlıklı bağlanmasın sağlandığı, sağlığın korunup geliştirildiği, fizyolojik ve psikolojik süreçlerin gözlemlendiği bir süreçtir. Covid 19, Ağır Akut Solunum Sendromu olarak isimlendirilmektedir. Covid 19; MERS-CoV ve SARS-CoV virüslerine benzer olarak hayvanlardan insanlara bulaş gösteren zoonotik bir virüs olarak tanımlanmaktadır. Covid 19'un izolasyon gerektiren bir hastalık olması, lohusaların aile üyelerinden yeterli destek almasını etkilemektedir. Postpartum döneminin özelliklerinden dolayı zaten psiko-sosyal anlamda zorluk çeken lohusaların uymaları gereken karantina koşulları, daha derin psikolojik etkileri ve sosyal mesafe zorunlulukları bu hastalığa yakalanan lohusalarda yürütülecek hemşirelik bakımının özelleştirilmesi gerekliliğini ortaya çıkarmıştır. Bu çalışmada, Covid 19 pozitif bir lohusanın hemşirelik bakımı Orlando'nun etkileşim modeli doğrultusunda değerlendirilerek olgu olarak sunulmuştur. Çalışma öncesinde Lohusadan sözlü ve yazılı izin alınmıştır. Lohusanın klinikte yattığı 3-9 Mayıs 2020 tarihleri arasında veriler yüz yüze görüşme yöntemi ile toplanmıştır. Orlando'nun etkileşim modeli kullanılarak hastanın ihtiyaçları belirlenmiş, bakımı hemşirelik süreci doğrultusunda planlanmış, uygulanmış ve sonuç olarak hastanın davranışlarında pozitif iyileşme süreci görülmüştür. Orlando'nun etkileşim modelinin psikiyatri ve kadın doğum gibi diğer kliniklerde de uygulanması önerilmektedir.
\end{abstract}

Anahtar Kelimeler: Orlando, Etkileşim Modeli, Covid 19, Lohusa.

\section{ABSTRACT}

Recently, the use of theories in nursing, which is a professional profession, is increasing. Nursing theories and models serve as guidance for nurses in the fields of education, research, and practice. It distinguishes the professional nursing profession from other occupational groups and improves the quality of the care offered to the patient. One of the models used is Orlando's Nursing Process Theory.The period of puerperium is a process in which healthy connection between mother baby and family members is ensured, health is protected and improved, physiological and psychological processes are observed. Covid 19 is called Severe Acute Respiratory Syndrome. Covid 19; Similar to mers-cov and SARS-CoV viruses, it is described as a zoonotic virus that infects people from animals to humans. Covid 19 is a disease that requires isolation, affecting lohusas to get adequate support from family members. As one of the features of the postpartum period, the deeper psychological effects and social distance requirements of the puerperant woman that are already psycho-socially difficult to follow have revealed the need to privatize nursing care to be carried out in lohusas caught up in this disease.In this study, puerperant woman diagnosed with COVID 19 in the clinic was applied to provide nursing care using the Nursing Process Theory of Orlando. Verbal and written permission was obtained from the puerperant woman before the study. Between 3-9 May 2020 , when puerperant woman was in the clinic, the data was collected by face-to-face interview method. Orlando's nursing process theory was determined by the patient's needs, planned, implemented in accordance with the nursing process for nursing actions, and as a result, a positive improvement process was observed in the patient's behavior. Orlando's Nursing Process Theory is also recommended in other clinics, such as psychiatry and obstetrics.

Keywords: Orlando, Nursing Process Theory, Covid 19, Puerperant Woman.

\footnotetext{
${ }^{1}$ Uzm. Hem. Nazlı Emel ÖZER YURDAL, Uzm. Hemşire-Doktora Öğrencisi, Aydın Adnan Menderes Üniversitesi, Doğum-Kadın Sağlığı ve Hastalıkları Hemşireliği Anabilim Dalı, emelozer18@ hotmail.com ORCID: 0000-0003-2559-969X

${ }^{2}$ Prof. Dr. Hilmiye AKSU, Aydın Adnan Menderes Üniversitesi, Doğum-Kadın Sağlığı ve Hastalıkları Hemşireliği Anabilim Dalı, hilmiyeaksu@yahoo.com, ORCID: 0000-0001-6975-3172
} 
Profesyonel bir meslek olan hemşirelik alanında model kullanımı son zamanlarda giderek artmaktadır. Modeller hemşirelere eğitim, araştırma ve uygulama alanlarında rehberlik görevi görürler. Profesyonel olan hemşirelik mesleğini diğer meslek gruplarından ayırarak hastaya sunulan bakımın kalitesini artırırlar. $^{1}$ Kullanılan modellerden birisi de Orlando'nun hemşirelikte etkileşim modelidir.

Lohusalık dönemi, anne bebek ve aile üyeleri arasındaki sağlıklı bağlanmanın sağlandığı, sağlığın korunup geliştirildiği, fizyolojik ve psikolojik süreçlerin gözlemlendiği bir süreçtir. ${ }^{2}$ Postpartum dönem hem anne hem de bebeğin hemşirelik bakımına ihtiyaç duydukları bir dönem olup, bu dönemde basit düzeyde sorunların çözümünde bile bakıma ihtiyaç duyabilirler. Postpartum dönemde verilen hemşirelik bakımı ve bakımın niteliği önemlidir. $\mathrm{Bu}$ süreçte anneler yenidoğan bakımı, emzirme, meme bakımı, uyku sorunları, konstipasyon, bebekle iletişim kurma, annelik rolü, depresyon gibi ruhsal sorunlar dahil bir çok sorun ile yüzleşmektedir. ${ }^{1-5} \mathrm{Bu}$ süreçte hemşireler tarafından yapılan anne-bebek ziyaretlerinde, anne bebek etkileşimi gözlemlenmelidir. Anne ve bebeğin fiziksel sağlığı, annenin ruhsal sağlığı, erken dönem komplikasyonları önlenmeli, annenin ve eşin yeni rollerine uyumu değerlendirilmelidir. ${ }^{6-11}$

Covid 19, Ağır Akut Solunum Sendromu olarak isimlendirilmektedir. Covid 19; MERS-CoV ve SARS-CoV virüslerine benzer olarak hayvanlardan insanlara bulaş gösteren zoonotik bir virüs olarak tanımlanmaktadır. ${ }^{12,13}$ Hızlı bulaş yolu, hasta ve ölüm oranlarında artışa sebep olması insanların korku yaşamasına zemin hazırlamıştır. Sağlık alanı dışında ülkelerin turizm, ekonomi, eğitim gibi alanlarını da etkilemiştir. Diğer yandan Covid 19'un izolasyon gerektiren bir hastalık olması, lohusaların aile üyelerinden yeterli destek almasını etkilemektedir. $\mathrm{Bu}$ yüzden hemşirelik bakımının nitelik ve niceliğinin artırılmasını gerektirmektedir. Postpartum döneminin özelliklerinden dolayı zaten

\section{GİRIȘ}

psiko-sosyal anlamda zorluk çeken lohusaların uymaları gereken karantina koşulları, daha derin psikolojik etkileri ve sosyal mesafe zorunlulukları bu hastalığa yakalanan lohusalarda yürütülecek hemşirelik bakımının özelleştirilmesi gerekliliğini ortaya çıkarmıştır. ${ }^{14}$

$\mathrm{Bu}$ çalışmada, Covid 19 pozitif bir lohusanın hemşirelik bakımı Orlando'nun etkileşim modeli doğrultusunda yapılmış ve olgu olarak sunulmuştur.

\section{Ida Jean Orlando’nun Etkileșim Modeli}

Ida Jean Orlando 1926 yılında dünyaya gelmiștir. 1947 y1lında hemșire olarak New York Tip Kolejinden mezun olup, 1954 yılında yüksek lisans mezuniyet derecesini almıștır. ${ }^{15}$

Orlando, etkileşim modelini hasta-hemșire iletişiminin gözlemlerinden yola çıkarak oluşturmuştur. Orlando hemşireliğin diğer bilimlerden bağımsız profesyonel bir alan olduğunu ifade etmiştir. ${ }^{14}$ Orlando'ya göre bireyler kendi gereksinimlerini kendileri karşılayamadıkları zaman hemşirelerin profesyonel bakımlarına ihtiyaç duyarlar. Hemşireler tarafından hastaların ihtiyaçları yeterli bir şekilde karşılanmadığı zaman hastalar kendilerini çaresiz ve sikıntılı hissederler. ${ }^{16-19}$ Orlando'ya göre birey yardıma ihtiyacı olduğunu sözlü olarak veya sözsüz olarak davranış şekilleriyle ifade eder. Hemşirenin bireyin gereksinimlerini karşılayabilmesi için hastayı yakından gözlemlemesi ve etkili iletişim kurması gerekir. $^{15}$

Orlando’ya göre amaçlı hemşirelik süreci üç temel bileşenden oluşmaktadır. Bunlar; hastanın davranışı, hemşirenin tepkisi ve hastanın iyiliği için düzenlenen hemșirelik eylemleridir. Hastanın davranışı: hemşirehasta arasındaki anlık olan iletişimde hemşirenin hastada gözlemlediği hem hastanın şikâyet etmesi ve sözlü ifadelerini içeren sözlü davranışları hem de ağlama, iç çekme titreme, ciltteki renk değişikliği gibi sözsüz davranıșları içermektedir. ${ }^{18}$ Orlando 
hastaların tedavilerinde ve bakımlarında red yanıtı verebileceğini, hemşirenin bu davranış1 hastanın sıkıntı yaşadığı için verdiğini fark etmesini ifade etmiștir. Böyle bir durumda hemşire hastanın davranışı ile daha yakından ilgilenmelidir. Hemşirenin tepkisi: hemşire hasta ile ilgili verileri toplarken hastanın davranışlarının farkına varıp davranışları algılar böylece konu hakkında düşünce ve duyguları oluşur. Hemşirelik eylemi: hemşirenin tepkisine göre oluşturduğu hemşirelik girişimleridir. Hemşirelik eylemleri iki farklı biçimde görülebilir. Bunlar otomatik ve amaçlı hemşirelik eylemleridir. Otomatik hemşirelik eylemleri; Hastanın o an dışındaki ihtiyaçlarından başka sebeplere yönelik kararları içerir. Amaçlı hemşirelik eylemleri; hastanın o an içindeki ihtiyaçlarına yönelik hazırlanan hemşirelik eylemlerini içerir. ${ }^{19}$

Bireyin aktif olarak bakıma dâhil edildiği modelin merkezini birey oluşturmaktadır. Farklı bölümlerde hemşirelerin uygulamasına olanak sağlar. Hemșire ve hasta arasındaki iletişimi kuvvetlendirmesi, hemşirelere otonomi kazandırması modelin güçlü yönlerini oluşturur. Modelin zayıf özellikleri; bakım süresi kısadır, bilinci kapalı hastalara uygulanamaz, ailenin etkisinden bahsedilmemiştir. ${ }^{15}$

Orlando'nun kuramı, karşılıklı ilişki olarak tanımlanabilir. Burada temel amaç, hastanın gereksiniminin karşılanarak sıkıntısının giderilmesidir. $\mathrm{Bu}$ gereksinimin karşılanmasında önemli olan, etkin bir hasta/hemşire ilişkisidir.

Orlando'ya göre hemşirelik bir süreçtir ve bu süreç içinde temel olan dört uygulama vardir:

- Gözlem,

- Sözlü rapor,

- Kaydetme (yazilı rapor),

- Hasta ile ya da hasta için yapılan faaliyetler.

\section{OLGU SUNUMU}

34 yaşında, üniversite mezunu ve ev hanımı olan lohusanın dört yaşında bir çocuğu vardır. 26 Nisan 2020 tarihinde normal spontan vajinal doğum ile 3500 gram ağırlığında sağlıklı bir kız çocuğu dünyaya getirmiştir. Doğumdan 7 gün sonra ateş, ağrı ve öksürük şikâyetleri ile hastanenin acil servisine başvuru yapmıştır. Acil servisten kliniğe yatışı gerçekleşmiştir. EKG ve akciğer grafisi normal değerlendirilmiştir. Covid 19 test sonucu pozitif gelmiştir. Alınan öyküsü ve yapılan fiziksel muayenesinde sistemik ve kronik bir hastalığı olmadığı, herhangi bir ilaç ve alerji öyküsü olmadığ 1 , sigara ve alkol kullanmadığı saptanmıştır. Yapılan laboratuvar analizlerine göre kan ve idrar sonuçlarının normal olduğu tespit edilmiştir. Lohusanın kan basınc1 100/60 mmHg, nabz1 70 atım $/ \mathrm{dk}$, ateşi ilk iki gün $38^{\circ} \mathrm{C}$, diğer günler $36.8^{\circ} \mathrm{C}$, SAO2 değeri $\% 97$ olarak kayıt edilmiştir.

Lohusa klinikte yattığı 3-9 Mayıs 2020 tarihleri arasında tedavi ve bakım almıştır. Veriler yüz yüze görüşme yöntemi ile toplanmıştır. Orlando etkileşim modeline göre lohusadan toplanan veriler; lohusa ile yapılan görüşmelerde lohusanın sürekli uyuduğu, bazen sakin bazen yorgun, uykulu olduğu, kısa cümleler kurduğu belirlenmiştir. Kendisini ümitsiz hissediyordu. İlk günler göz temasinı fazla kurmuyordu. Yeterli su içmiyordu. Lohusa kendi tercihi ile, bebeğin kendisinden uzak kalmasını talep etti. Bunun altında yatan neden lohusanın, bebeğin enfeksiyon kapacağı yönündeki kaygılarıydı. $\mathrm{Bu}$ nedenle sütü sağılarak bebeğe ulaştırıldı. Çocuklarını göremediği için üzgün olduğunu, bebeğini emziremediği için kendini suçlu hissettiğini, hastalığının gidişatı ile ilgili ümitsizlik ve korku yaşadığını söylüyordu. Ayrıca memelerinde dolgunluk şikâyeti yaşadığını ifade etti.

Lohusaya; aile içi süreçlerin devamlılığında bozulma, emzirmenin kesintiye uğraması, ümitsizlik, bilgi eksikliği, korku, enfeksiyon bulaştırma riski hemşirelik tanıları konulmuş ve bu tanılar doğrultusunda hemşirelik girişimleri uygulanmış ve değerlendirilmiştir. Orlando'nun Amaçlı Hemşirelik Sürecine göre lohusaya yapılan 


\section{Araștırmanın Etik Yönü}

veriler "Gözlemler, Faaliyetler, Raporlama ve Kayıt Tutma olarak dört başlıkta toplanmıştır.

\section{BULGULAR VE TARTIŞMA}

\section{Gözlemler}

Doğrudan Gözlemler: Hemşirenin Hastanın Davranışına Yönelik Tepkisi

- Lohusanın sürekli uyuması

- Kisa cümleler kurması

- Yorgun gözükmesi

- İlk günler göz temasını kısa süreli kurmasi

- Bebeğini emziremediği için kendisini suçlu hissettiğini ifade etmesi

- Hastalıkla ilgili korku yaşadığını ifade etmesi

- Çocuklarını göremediği için kendisini üzgün hissettiğini ifade etmesi

\section{Dolaylı Gözlemler: Hastanın Davranışı Ile İlgili Diğer Bilgiler}

Lohusa, serviste yattığı günden beri bakım veren diğer hemşirelerle görüşmede lohusanın genel durumu konuşulmuş benzer davranışların, ifadelerin olduğu öğrenilmiştir.

\section{Faaliyetler}

Hemşirenin Faaliyeti: Amaçlı Hemşirelik

\section{Süreci}

\section{Doğrudan Yardım}

- Lohusaya Covid 19 hastalığı, bulaştırmanın önlenmesi için yapılması gerekenler, tedavi süreci, kullanılan ilaçlar hakkında bilgi verildi.

- Bağışıklık sistemini güçlendirmek, konstipasyon oluşumunu engellemek için yeterli beslenmesi ve sıvı alması desteklendi. Odasina su getirildi ve içmesi için cesaretlendirildi.
- Odasının belli aralıklarla havalandırılması sağlandı.

- Oda içinde hareket etmesi desteklendi.

- Duygularını ifade etmesi için cesaretlendirildi.

- Memelerine masaj yapıldı. Sütün pompa ile sağılması gösterilerek öğretildi. Kaba alınan anne sütünün bebeğine verileceği söylendi.

- Telefon verilerek eşi ve çocukları ile görüşmesi sağlandı.

- Annenin bebeğinin enfeksiyon kapacağına dair kaygıları giderilerek bebeği ile beraber kalmaya başlaması sağlandi. Anne önce kaşık ile bebeğini besledi daha sonra emzirdi.

\section{Dolaylı Yardım}

Lohusanın sütünün sağılması için süt pompası ve kap ve eşi ile konuşabilmesi için telefon hastane dişından temin edildi.

\section{Raporlama}

Sözel Olmayan Davranışları

- Uyku halinin azalması

- Dinç görünmesi

- İletişime istekli ve göz teması kurmaktan çekinmiyor olması

Sözel Davranışları

- Çocuklarını görüntülü arama ile gördüğü için mutlu olduğunu ifade etmesi

- Kap ile bebeğini besleyebildiği için içinin rahat ettiğini söylemesi

- Memede dolgunluk şikâyetinin geçtiğini ifade etmesi 
- Daha az uyuduğunu, kitap okuduğunu, telefon ile çocuğu ve eşi ile daha fazla vakit geçirdiğini ifade etmesi

- Hastalığa ilişkin korkusunun olmadığını ifade etmesi

- $\mathrm{Bu}$ sürecin doğal olduğunu, herkesin hasta olabileceğini, hastaneden sonra evde de verilen bilgileri uygulayacağını, kendisini artık suçlamadığını ve çocuklarını, eşini evde göreceği için heyecanlı hissettiğini ifade etmesi

\section{Kayit Tutma}

Lohusanın yardım ihtiyaçları karşılanmıştır. Etkili hemşirelik bakımı sonucu ortaya çıkmıștır. Lohusanın sözel ve sözel olmayan davranışlarında olumlu gelişmeler gözlemlenmiştir.

Orlando'nun Etkileşim Hemşirelik modeli, hemşire-hasta ilişkisini pozitif yönde geliştirmekte, hasta-hemşire etkileşimini özgün kılmakta, hastaların fiziksel ve ruhsal ihtiyaçlarının karşılanmasında hemşirelere yardımc1 olmaktadır. ${ }^{20-25}$ Hemşireler hastaların ihtiyaçları doğrultusunda uygun hemşirelik girişimlerini planlarlar ve uygularlar. Süreç sonunda hastaların sözel ve sözel olmayan davranışlarında olumlu yönde gelişimler olduğu yapılan bazı çalışmalarda görülmüştür. ${ }^{26-29}$

\section{SONUÇ VE ÖNERÍLER}

Hemşirelerin verdikleri bakımların etkinliğinin artırılmasında, profesyonel bir meslek olan hemşirelik mesleğinin gelişmesinde, bakımın bireyselleşmesinde modellerin kullanımı önemli bir rol oynamaktadır. Orlando'nun etkileşim modeli psikiyatri kliniklerinin yanında kadın doğum klinikleri de dâhil olmak üzere tüm kliniklerde çalışan hemşireler tarafından kullanılabilmektedir. Vaka sunumunda
Orlando'nun etkileșim modeli kullanılarak hastanın ihtiyaçları belirlenmiş, hemşirelik eylemleri amaçli hemşirelik süreci doğrultusunda planlanmış, uygulanmış ve sonuç olarak hastanın davranışlarında pozitif iyileşme süreci görülmüştür. Orlando'nun etkileşim modelinin psikiyatri ve kadın doğum gibi diğer kliniklerde de uygulanması önerilmektedir.

\section{KAYNAKLAR}

1. Kirlek, F. ve Can.Öztürk, H. (2016). Postpartum Dönem. Sevil Ü. Ertem G. Perinatoloji ve Bakım. Ankara: Nobel Tıp Kitabevleri.

2. Beydağ, K.D. (2007). "Doğum Sonu Dönemde Anneliğe Uyum ve Hemşirenin Rolü’. TAF Preventive Medicine Bulletin, 6 (6), 479-484

3. Gülec,, D, Kavlak, O. ve Sevil, Ü. (2014). "Ebeveynlerin Doğum Sonu Yaşadıkları Duygusal Sorunlar ve Hemşirelik Bakimı". Journal of Education and Research in Nursing, 11 (1), 54-63.

4. Bağcı, S. (2014). Annelerin Doğum Sonunda Yaşadıkları Sorunlar Ve Yaşam Kalitesi İle İlişkisi. Yüksek Lisans Tezi. Selçuk Üniversitesi Sağlık Bilimleri Enstitüsü, Konya.

5. Üstgörül, S. ve Yanıkkerem, E. (2017). "Postpartum Dönemde Kadınların Psikososyal Durumları ve Etkileyen Risk Faktörleri”. JAREN/Hemşirelik Akademik Araştırma Dergisi, 3 (1), 61-68.

6. Yıldız, D. (2008). "Doğum Sonrası Dönemde Annelerin Bebek Bakımı Konusunda Danışmanlık Gereksinimleri Ve Yaklaşımlar”. Gülhane Tıp Dergisi, 50, 294-298.

7. Jansson, A, Sivberg, B, Larsson, B.W. and Udén, G. (2002). "First-Time Mothers' Satisfaction with Early Encounters with The Nurse in Child Healt-Care: Home Visit or Visit To The Clinic?". Acta Paediatrica, 91, 571-577.
8. Frei, I.A. and Mander, R. (2011). "The Relationship between First-Time Mothers and Care Providers in The Early Postnatal Phase: An Ethnographic Study in A Swiss Postnatal Unit". Midwifery, 27, 716-722.

9. Yıldız, D. ve Akbayrak, N. (2014.) "Doğum Sonrası Primipar Annelere Verilen Eğitim ve Danışmanlık Hizmetlerinin Bebek Bakımı, Kaygı Düzeyleri ve Annelik Rolüne Etkisi”. Gülhane Tip Dergisi, 56, 36-41.

10. Razurel, C, Bruchon-Schweitzer, M, Dupanloup, A, Irion, O. and Epiney, M. (2011). "Stressful Events, Social Support and Coping Strategies of Primiparous Women During The Postpartum Period: A Qualitati- and Study". Midwifery, 27, 237-242.

11. Yalçın, S. (2020). Diş Hekimliğinde Yeni Dönem Covid-19 Pandemisi ve Alınacak Önlemler. Quintessence Yayıncılık, İstanbul. https://www.eotdental.com/uploads/pdf/serhatyalcin-covid-19-makale.pdf Erişim Tarihi:16.05.2020.

12. T.C. Sağlık Bakanlığı. (2020). https://covid19bilgi.saglik.gov. tr/ Erişim Tarihi:16.05.2020.

13. Baykara, Z.G, Calısskan, N. Öztürk, D. ve Karadă̆, A. (2019) "Hemşirelikte Teori Ve Model Kullanımı: Nitel Bir Çalışma". Cukurova Med J, 44 (1), 281-289. 
14. Yılmaz Esencan, T. ve Şimşek, Ç. (2017). "Doğum Sonu Dönemde Hemşirelik Bakımı". Zeynep Kamil Tıp Bülteni, 48, 183-189

15. Ekim, A, Ocakçı, A.F. ve Alpar, Ş.E. (Ed). (2013). Hemşirelikte Kavram, Kuram ve Model Örnekleri. İstanbul: İstanbul Tip Kitabevi.

16. Velioğlu, P. (1999). Hemşirelikte Kavram ve Kuramlar. İstanbul: Alaş Ofset.

17. Fawcett, J. (2005). Orlando's Theory of the Deliberative Nursing Process. Ed. Contemporary Nursing Knowledge Analysis and Evaluation of Nursing Models and Theories. F. A. Davis Company, Philadelphia, 506-527.

18. Parker, L.M. (2005). Twentieth-Century Nursing Wiedenbach, Henderson, and Orlando's Theories and Their Applications. Gesse T, Dombro M, Gordon SC, Rittman MR, ed. Nursing Theories and Nursing Practice. F. A. Davis Company, Philadelhia: 73-77.

19. Hiçdurmaz, D. (2017). Ida Jean Orlando: Hemşirelik Süreci Teorisi. A. Karadağ, N. Çalışkan, Z. Göçmen Baykara (Ed.), Hemsirelik teorileri ve modelleri. İstanbul: Akademi Basın ve Yayıncılık.

20. Olson, J. and Hanchett, E. (1997). "Nurse-Expressed Empathy, Patient Outcomes, and Development of A MiddleRange Theory". Image: The Journal of Nursing Scholarship, 29 (1),71-76.

21. Abdoli, S. and Safavi, S.S. (2010). "Nursing Students' Immediate Responses To Distressed Clients Based On Orlando's Theory". Iranian Journal of Nursing and Midwifery Research, 15 (4),178-184.
22. Dobson, L.N.M. (2012) "Foundations of The Routes of Care in The Pediatric Patient". Revista Cubana de Enfermería, 28 (2), 181-188

23. Potter, M.L, Williams, R.B. and Costanzo, R. (2004). "Using Nursing Theory And A Structured Psychoeducational Curriculum With Inpatient Groups". Journal of the American Psychiatric Nurses Association, 10, 122-128.

24. Prá, L.A. and Piccoli, M. (2004). "Perioperatıve Nursıng: Nursing Diagnosis Based The Theory Of Ida Jean Orlando". Revista Eletrônica de Enfermagem, 6 (2), 234-253.

25. Sheldon, L.K. and Ellington, L. (2008). "Application of A Model of Social Information Processing To Nursing Theory: How Nurses Respond To Patients". Journal of Advanced Nursing, 64 (4), 388-398.

26. Dündar, T. ve Gerçek, E. (2020). "Hemşirelikte Etkileşim Kuramının Postpartum Dönemde Kullanımı: Bir Olgu Sunumu”. EGE HFD, 36 (1), 67-72.

27. Can, S, Yıldırım Usta, Y. ve Can Çiçek, S. (2019) “Orlando'nun Hemşirelik Süreci Teorisi'nin Uygulamada Kullanımına Bir Örnek: Olgu Sunumu”. Diyabet, Obezite ve Hipertansiyonda Hemşirelik Forumu Dergisi, 11 (1), 46-48.

28. Akyüz, E, Uğurlu, Z. Cevik, B, Yaman, C. ve Ayhan, A (2017). "Leiomyosarkom Tanılı Bir Gebenin Ida Jean Orlando'nun Etkileşim Modeline Göre İncelenmesi: Vaka Sunumu". Başkent Üniversitesi Sağlık Bilimleri Fakültesi Dergisi-BÜSBİD, 2 (1), 73-78.

29. Uslu, N, Bayat, M, Variyenli, N, Arıcan, F. ve Hatipoğlu, N (2016). "Orlando'nun Etkilessim Teorisinin Uygulamada Kullanımına Bir Örnek: Tip 1 Diyabetes Mellitus”. Yıldırım Beyazıt Üniversitesi Hemșirelik E-Dergisi, 3 (1), 64-70. 